\title{
Propriedade intelectual e fomento à Pesquisa, Desenvolvimento e Inovação: considerações sobre a portaria $\mathrm{CNPq}^{0} \mathbf{5 0 2 / 2 0 2 1}$
}

\author{
Intellectual property and Research, Development and Innovation incentives: CNPq administrative
}

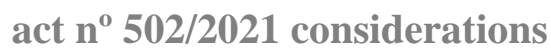

Propiedad industrial y fomento de la Investigación, desarrollo e innovación: consideraciones sobre la normativa administrativa $\mathrm{CNPq} \mathrm{n}^{0}$ 502/2021

\author{
Alejandro Knaesel Arrabal \\ ORCID: https://orcid.org/0000-0002-0927-6957 \\ Fundação Universidade Regional de Blumenau, Brasil \\ E-mail: arrabal@furb.br \\ Vinicyus Rodolfo Wiggers \\ ORCID: https://orcid.org/0000-0003-2273-8025 \\ Fundação Universidade Regional de Blumenau, Brasil \\ E-mail: vwiggers@furb.br \\ Otávio Henrique Baumgarten Arrabal \\ ORCID: https://orcid.org/0000-0003-4960-1002 \\ Fundação Universidade Regional de Blumenau, Brasil \\ E-mail: oarrabal@furb.br \\ Ana Paula Colombo \\ ORCID: https://orcid.org/0000-0002-9087-3555 \\ Fundação Universidade Regional de Blumenau, Brasil \\ E-mail: apcolombo@furb.br \\ Rodrigo dos Santos Cardoso \\ ORCID: https://orcid.org/0000-0002-3376-9567 \\ Fundação Universidade Regional de Blumenau, Brasil \\ E-mail: rodrigocardoso@furb.br \\ Erly Ian da Silva Santos \\ ORCID: https://orcid.org/0000-0002-5445-9234 \\ Fundação Universidade Regional de Blumenau, Brasil \\ E-mail: eissantos@furb.br
}

\begin{abstract}
Resumo
Esse estudo analisa e comenta a Portaria 502 do Conselho Nacional de Desenvolvimento Científico e Tecnológico (CNPq), de 12 de maio de 2021, a qual institui regras de Direito de Propriedade Intelectual aplicáveis às relações do Conselho com executores de projetos, bolsistas e pesquisadores beneficiados por instrumentos de fomento, bem como demais parceiros vinculados aos beneficiários. O trabalho revela interfaces da portaria com a legislação sobre Direitos de Propriedade Intelectual, bem como às normas relacionadas ao incentivo à inovação e ao acesso à informação. $\mathrm{O}$ estudo indica que, embora a disciplina sobre o assunto não seja nova no âmbito do $\mathrm{CNPq}$, a portaria reitera sistemicamente a importância do compromisso que os beneficiários de fomento devem assumir na gestão e tutela de Direitos de Propriedade Intelectual, em prol do desenvolvimento nacional socioeconômico. Também considera a necessidade de aperfeiçoamento das diretrizes da CAPES sobre a matéria, a fim de acolher de forma mais efetiva a valorização de Títulos de PI como indicadores de qualidade dos programas de pós-graduação nacionais.
\end{abstract}

Palavras-chave: Fomento; Pesquisa; Inovação; Propriedade intelectual.

\begin{abstract}
This study analyzes and comments the Administrative Act 502 of the Brazilian National Council for Scientific and Technological Development (CNPq), of May 12, 2021, which institutes Intellectual Property Law rules applicable to the Council's relations with R,D\&I project executors, fellows and researchers benefited by applications, as well as other partners linked to the beneficiaries. The work reveals interfaces between the administrative act and the Brazilian Statutory Intellectual Property rights, as well as the norms related to encouraging innovation and access to information. The study indicates that, although the discipline on the subject is not new within the scope of the CNPq, the administrative act systematically reinforce the importance of the commitment that incentives beneficiaries must assume the management and protection of intellectual property rights, in favor of social and national economic development. It also considers that CAPES (the Brazilian Coordination for the Improvement of Higher Education Personnel) needs to
\end{abstract}


improve the guidelines on the subject, in order to more effectively include the valuation of IP titles as quality indicators of national undergraduate and graduate programs.

Keywords: Incentives; R,D\&I; Innovation; Intellectual property.

\section{Resumen}

Este estudio analiza y comenta la Normativa administrativa 502 del Consejo Nacional de Desarrollo Científico y Tecnológico (CNPq), de 12 de mayo de 2021, que instituye las normas de Derecho de la Propiedad Industrial aplicables a las relaciones del Consejo con los ejecutores de proyectos, becarios e instrumentos de desarrollo de investigadores beneficiados. El trabajo revela interfaces entre la Normativa y la legislación sobre derechos de propiedad intelectual, así como las normas relacionadas con el fomento de la innovación y el acceso a la información. El estudio indica que, si bien la disciplina sobre el tema no es nueva en el ámbito del CNPq, la Normativa reitera sistemáticamente la importancia del compromiso que deben asumir los beneficiarios del desarrollo en la gestión y protección de los Derechos de Propiedad Industrial, a favor de la economía socioeconómica nacional. desarrollo. También considera la necesidad de mejorar las Normativas de la Coordinación para la Perfeccionamiento del Personal de Educación Superior (CAPES) sobre el tema, a fin de adoptar de manera más eficaz la valoración de los títulos de propiedad intelectual como indicadores de calidad de los programas nacionales de posgrado.

Palabras clave: I+D+I; Investigación; Innovación; Propriedad industrial.

\section{Introdução}

O mercado corresponde a "expressão de um projeto político - como princípio de organização social - e atividade" (Grau, 2021, p. 17), no qual agentes econômicos colocam à disposição bens e serviços que, em grande parte, resultam da pesquisa e desenvolvimento ${ }^{1}$ por eles gestados ou promovidos em parceria com Instituições de Ciência, Tecnologia e Inovação, apoiadas pelo Estado.

Instituído pela Lei $\mathrm{n}^{\circ}$ 1.310, de 15 de janeiro de 1951, o Conselho Nacional de Desenvolvimento Científico e Tecnológico $(\mathrm{CNPq})$ apresenta-se à sociedade como uma organização primordial para o fomento à Pesquisa, Desenvolvimento e Inovação no Brasil. Ela representa a manifestação de uma infraestrutura científica que assume papel relevante, em particular no contexto de um sistema nacional de inovação ainda em desenvolvimento (Suzigan, Albuquerque, Cario, 2011, p. 9).

Vale (2019, p. 344), ao propor o Princípio da Inovação Tecnológica Democrática, menciona que toda ${ }^{2}$ pessoa, seja ela natural ou jurídica, pode se dedicar à inovação tecnológica e às atividades que dela decorram. A missão técnica e social do CNPq proporciona ao País, além da concretização material dos possíveis resultados dos projetos de P,D\&I fomentados, a realização da liberdade da pesquisa científica que integra a vontade de conhecer e a liberdade para conhecer (Lima, 2020).

A possibilidade de retorno financeiro ao investimento realizado se dá majoritariamente pelos mecanismos da propriedade intelectual, que possibilitam a gestão de direitos sobre bens incorpóreos. No contexto dos parques tecnológicos, Giglio (2019, p. 97) considera que estes bens constituem elementos do "estabelecimento empresarial", que se revelam "necessários ao desenvolvimento da atividade empresária, além dos demais atores como universidades e instituições de pesquisa." Portanto, quando da execução de projetos de P,D\&I, a gestão de direitos a partir de mecanismos jurídicos de PI se mostra fundamental.

\footnotetext{
${ }^{1}$ Wald (2010), na perspectiva do moderno Direito Empresarial, apresenta que "a revolução empresarial justifica, pois, que a empresa não mais se identifique exclusivamente com o seu proprietário ou controlador, mas represente também a sua diretoria, seus executivos, seus técnicos, seus trabalhadores, ou seja as equipes e os equipamentos que constituem o todo. Tal fato também decorre de não mais se considerar como únicos fatores de produção o capital e o trabalho, mas de se incluir, entre os mesmos, dando-lhe a maior relevância, o saber, ou seja a tecnologia, que assegura a produtividade da empresa e na realidade o seu presente e o seu futuro, abrangendo tanto as técnicas industriais e comerciais como a própria técnica de gestão." (grifamos)

${ }^{2}$ Aqui, não há de se olvidar das perspectivas críticas, sobretudo do ponto de vista da Universidade, que afirmam ser necessário um tratamento cauteloso quando da relação mercadológica que a inovação pressupõe. Um exemplo é de Travincas (2018), ao observar que "a relação entre Academia e mercado é bidirecional - é sincero admitir que aquela seja tocada por esse último, mas o contrário também é verdadeiro. E esse desenho aponta para o cabimento de ajustes de interesses, muito mais que para a supressão das balizas que mantêm erguida qualquer uma das duas searas. Algum nível de isolamento das aspirações de mercado é condição sine qua non para a manutenção dos fins da educação e das Instituições educacionais em particular."
} 
Considerando estes aspectos, o presente estudo analisa e comenta a Portaria 502 do Conselho Nacional de Desenvolvimento Científico e Tecnológico (CNPq), de 12 de maio de 2021, a qual institui regras de Direito de Propriedade Intelectual aplicáveis às relações do Conselho com executores de projetos, bolsistas e pesquisadores beneficiados por instrumentos de fomento, bem como demais parceiros vinculados aos beneficiários. $\mathrm{O}$ trabalho revela interfaces da portaria com a legislação sobre Direitos de Propriedade Intelectual, bem como às normas relacionadas ao incentivo à inovação e ao acesso à informação.

Desenvolvido a partir dos principais eixos temáticos que estruturam a portaria, o artigo apresenta seis unidades. A primeira explora a noção dogmática de "fomento" e sua relação com a pesquisa, desenvolvimento e inovação. A segunda aborda o escopo da portaria CNPq n n $^{\circ}$ 52/2021 e sua respectiva aplicação. A terceira comenta os dispositivos relacionados ao dever de zelo para a garantia de Direitos de Propriedade Intelectual. Por sua vez, a quarta desenvolve as questões de titularidade, gestão e partilha de resultados sobre os Direitos de Propriedade Intelectual de criações resultantes de atividades destinatárias de fomento. A quinta unidade explicita os parâmetros que balizam a publicidade de informações e resultados dos projetos, e, por fim, a sexta unidade descreve as condições parra solução de conflitos relacionados ao teor da portaria.

\section{Metodologia}

O estudo coteja as orientações da Portaria 502 do Conselho Nacional de Desenvolvimento Científico e Tecnológico (CNPq), de 12 de maio de 2021, com a legislação nacional que disciplina direitos de propriedade intelectual e inovação, mais especialmente a Lei $\mathrm{n}^{\circ}$ 9.279, de 14 de maio de 1996, que regula direitos e obrigações relativos à propriedade industrial, bem como a Lei no 10.973/2004 que dispõe sobre incentivos à inovação e à pesquisa científica e tecnológica no ambiente produtivo, atualizada pela Lei $\mathrm{n}^{\circ} 13.243 / 2016$. Nesse sentido, o estudo apresenta natureza qualitativa, cujo método de procedimento compreende o interpretativista e análise de conteúdo. A pesquisa qualitativa, segundo Minayo (2002, p. 21-22), "trabalha com o universo de significados, motivos, aspirações, crenças, valores e atitudes, o que corresponde a um espaço mais profundo das relações, dos processos e dos fenômenos que não podem ser reduzidos à operacionalização de variáveis". Nesse viés, o método interpretativista (Prolo, Lima, Silva, 2018) permite explorar o sentido e alcance de normas, considerando as nuances da realidade a que elas se destinam. Complementarmente, para Bardin (2016), a análise de conteúdo aplica-se a discursos diversos, o que inclui expressões de caráter normativo em seus conteúdos e continentes, como é o caso do presente estudo.

\section{Noção Dogmática de “fomento" e sua Relação com a Pesquisa, Desenvolvimento e Inovação}

No contexto contemporâneo, o fomento à Pesquisa, Desenvolvimento e Inovação é atravessado por diversas questões. Por um lado, há quem reconheça (e assim está constitucionalmente estabelecido ${ }^{3}$ ) que ao Estado cumpre a responsabilidade de contribuir com o desenvolvimento científico e tecnológico. Por outro, a escassez de recursos públicos, dada a pluralidade de demandas sociais, somada ao ideário de aproximação com o setor privado, coloca em pauta modelos institucionais orientados ao compartilhamento de riscos. Assim, demandas de interesse público podem ser atendidas pelo setor privado, com o fomento estatal (Marques Neto, 2019).

O fomento representa uma forma indireta - não coercitiva - de intervenção estatal na economia, "capaz de viabilizar a satisfação de necessidades e interesses públicos com mínima restrição na liberdade e propriedade privada, e sem que o Estado assuma para si a prestação de uma atividade" (Marques Neto, 2019). É, portanto, em síntese, “ato de promover o desenvolvimento de uma atividade econômica." (Othon Sidou, 2016, p. 185).

\footnotetext{
3 “Art. 23. É competência comum da União, dos Estados, do Distrito Federal e dos Municípios: [...] V - proporcionar os meios de acesso à cultura, à educação, à ciência, à tecnologia, à pesquisa e à inovação;” (Brasil, CRFB/88).
} 
Precisamente, quanto ao contexto do fomento em P,D\&I no campo do ensino:

[...] a subvenção constitui-se em instrumento relevante de fomento estatal, uma vez que se trata de atividades com alto risco, sendo que apenas um porcentual muito pequeno resultará em produtos capazes de efetivamente gerar retorno financeiro com sua posterior exploração - mas que, ainda assim, geram benefícios extremamente relevantes para a sociedade. Por essa razão, o setor público, em diferentes esferas (notadamente instituições de pesquisa e agências de fomento), oferecem bolsas de pesquisas e outros auxílios para o desenvolvimento de pesquisas e participação em eventos científicos. Tais concessões não são restituíveis, mas há diversos requisitos prévios (vinculação a um programa de pósgraduação, por exemplo) e contrapartidas (tal como o compromisso de posterior atuação profissional no país, por certo prazo) que devem ser observados pelos agentes que recebem os benefícios. [...] (Marques Neto, 2019).

A atuação estatal com o fomento se dá a partir da indução de ações por parte dos agentes econômicos, que assim atuarão de forma voluntária, por meio de incentivos financeiros. Estes incentivos, devido a natureza da atividade de P,D\&I, estão suscetíveis à álea inerente àquela, pois que "está na essência dos atos praticados na intenção de se inovar tecnologicamente a aleatoriedade dos resultados atingidos" (Vale, 2018, p. 152).

\section{Escopo e Aplicação da Portaria CNPq n⿳0 502/2021}

Em sintonia com o artigo 30 da Lei $\mathrm{n}^{\circ} 13.655 / 2018$, o qual dispõe que "as autoridades públicas devem atuar para aumentar a segurança jurídica na aplicação das normas", segurança esta vinculada aos ideais de determinação, estabilidade e de previsibilidade do Direito (Ávila, 2019, p. 50), tão caros ao regime publicístico ${ }^{4}$, o CNPq publicou a Portaria no 502 de 12 de maio de 2021 com o propósito de estabelecer regras sobre a aplicação de Direito de Propriedade Intelectual às suas relações com instituições executoras de projetos, bolsistas e pesquisadores beneficiados pelos instrumentos de fomento, bem como demais parceiros que abrigam os beneficiários dos respectivos instrumentos (Art. $\left.1^{\circ}\right)^{5}$.

A Portaria revogou a Resolução Normativa n ${ }^{\circ}$ 34, de $1^{\circ}$ de setembro de 2014 (Art. 20) $)^{6}$, estabelecendo assim a reedição de ato normativo para adequação ao Decreto n 10.139 de 28 de novembro de 2019, que determinou e orientou "a revisão, a consolidação e a publicação na internet de todos os atos normativos inferiores a decreto com a finalidade de racionalizar, padronizar, simplificar e dar publicidade ampla às normas editadas pelo Executivo Federal.”

A dita resolução, portanto, já estipulava regras sobre direitos e deveres para criações intelectuais resultantes de pesquisas apoiadas por instrumentos de fomento, auxílios e bolsas disponibilizados pelo CNPq. Cumpre observar que o tema foi objeto de sucessivos atos regulatórios pela instituição desde a década de $80^{7}$, conforme se observa no quadro abaixo.

\footnotetext{
${ }^{4}$ Muraro (2020, p. 100) anota que o regime jurídico de direito público pode ser observado como "um sistema organizado e escalonado de comandos e atribuições para balizar a Administração Pública na elaboração e execução de políticas públicas em prol da sociedade", regime este abarcado com vigor e pujança nas ICTs públicas que por vezes apresentam dificuldades na definição interna de suas políticas de inovação para dialogar com a lógica e discurso tradicionalmente comercialistas da PI. É da mais absoluta importância perceber que este regime também regra sobremaneira o campo epistêmico-normativo dos Direitos de Propriedade Intelectual, pois que este "não é nunca uma relação privada pura." (Barbosa, Tomo III, 2014, p. 2023).

5 “Art. $1^{\circ}$ Esta norma define as regras do Direito de Propriedade Intelectual que se aplicam às relações entre o Conselho Nacional de Desenvolvimento Cientifico e Tecnológico - CNPq e as instituições executoras de projetos, bolsistas e pesquisadores beneficiados pelos instrumentos de fomento deste Conselho, bem como demais parceiros que abrigarem os beneficiários dos instrumentos de fomento."

6 “Art. 20. Fica revogada a Resolução Normativa n 34, de $1^{\circ}$ de setembro de 2014."

7 Vide: Resoluções CNPQ 114 e 115, de 1981; Resolução Normativa 14, de 1998; Resolução Normativa 13, de 2008; Resolução Normativa 34, de 2014; e a atual Portaria 502, de 2021.
} 
Quadro 1 - Série de normas do CNPq sobre direitos de propriedade intelectual

\begin{tabular}{|c|c|}
\hline Norma (ato administrativo) & Objeto \\
\hline Resolução 114, de 1981 & $\begin{array}{l}\text { Fixar as condições gerais de concessão, pelo } \mathrm{CNPq} \text {, de colaboração } \\
\text { financeira não-reembolsável e assegurar aos beneficiários, adiante } \\
\text { definidos, bem como aos empregados e prestadores de serviços desta } \\
\text { Fundação, os direitos previstos no art. } 42 \text { da lei no 5.772, de } 21 \text { de } \\
\text { dezembro de } 1971 \text { (Código da Propriedade Industrial) }\end{array}$ \\
\hline Resolução 115, de 1981 & $\begin{array}{l}\text { Estabelece as condições para o patenteamento de invenções e outros } \\
\text { direitos relativos à propriedade intelectual, em decorrência de trabalhos } \\
\text { realizados com a colaboração do CNPq ou por seus empregados e } \\
\text { prestadores de serviços }\end{array}$ \\
\hline Resolução Normativa 14, de 1998 & $\begin{array}{l}\text { Regulamentar a atribuição de direitos sobre criações intelectuais, no } \\
\text { âmbito do CNPq e de suas Unidades de Pesquisa, e a participação do } \\
\text { inventor nos ganhos econômicos decorrentes da exploração da patente ou } \\
\text { direitos de proteção conferidos. }\end{array}$ \\
\hline Resolução Normativa 13, de 2008 & $\begin{array}{l}\text { Regulamentar a atribuição de direitos sobre criações intelectuais } \\
\text { originadas a partir dos instrumentos de fomento - auxílios e bolsas - } \\
\text { disponibilizados pelo CNPq, e a participação nos ganhos econômicos } \\
\text { decorrentes da exploração de patente ou direito de proteção, conferidos a } \\
\text { estas criações. }\end{array}$ \\
\hline Resolução Normativa 34, de 2014 & $\begin{array}{l}\text { Regulamentar os direitos sobre criações intelectuais resultantes de } \\
\text { pesquisas apoiadas por instrumentos de fomento - auxílios e bolsas - } \\
\text { disponibilizados pelo CNPq, a participação nos ganhos econômicos } \\
\text { decorrentes da exploração de direitos de propriedade intelectual, bem } \\
\text { como o acesso às informações relacionadas aos projetos fomentados pelo } \\
\text { órgão. }\end{array}$ \\
\hline Portaria 502, de 2021 & $\begin{array}{l}\text { Art. } 1^{\circ} \text { Esta norma define as regras do Direito de Propriedade Intelectual } \\
\text { que se aplicam às relações entre o Conselho Nacional de Desenvolvimento } \\
\text { Científico e Tecnológico - CNPq e as instituições executoras de projetos, } \\
\text { bolsistas e pesquisadores beneficiados pelos instrumentos de fomento } \\
\text { deste Conselho, bem como demais parceiros que abrigarem os } \\
\text { beneficiários dos instrumentos de fomento. (destinatários, outorga) }\end{array}$ \\
\hline
\end{tabular}

Fonte: Brasil. CNPq.

Aplicável inclusive aos processos em curso no CNPq (Art. 18) ${ }^{8}$, a portaria considera criações intelectuais sujeitas a sua incidência: as invenções, modelos de utilidade, desenhos industriais, programas de computador, topografia de circuito integrado, marcas e novas variedades vegetais $\left(\text { Art. } 2^{\circ}\right)^{9}$.

Invenções, modelos de utilidade, desenhos industriais e marcas são bens cujo direito de exclusiva é regulado pela Lei $n^{\circ}$ 9.279/96 e pressupõe a obtenção de patente, para os dois primeiros, e registro para os outros dois. O direito sobre topografia de circuito integrado é previsto na Lei $\mathrm{n}^{\mathrm{o}}$ 11.484/07 e constitui-se também por meio de registro. O direito de exclusiva sobre nova variedade vegetal é obtido por meio de Certificado de Proteção de Cultivar, conforme dispõe a Lei nº 9.456/97.

A portaria não menciona explicitamente os Direitos de Autor. Tal se deve, provavelmente, em razão de que todas as criações enunciadas, ressalvado o Programa de Computador, exigem a obtenção de título ${ }^{10}$ constitutivo (Patente, Registro e Certificado) o que, por sua vez, pressupõe a adoção de providências, a fim de garantir a viabilidade da reivindicação do respectivo instrumento constitutivo, a exemplo do requisito de novidade exigido para as patentes. Já no caso de direitos autorais, estes se

\footnotetext{
8 "Art. 18. Esta Portaria se aplica a todos os processos em curso no CNPq"

9 “Art. $2^{\circ}$ Compreende-se, entre as criações intelectuais passíveis de proteção, as invenções, modelos de utilidade, desenhos industriais, programas de computador, topografia de circuito integrado, marcas, inclusive as tridimensionais, e novas variedades vegetais."

${ }^{10}$ Interessante é a observação, oriunda do direito espanhol, por maior atenção aos aspectos de um corpo de direito registral da propriedade industrial, proposto por González (2016): "La escasez de normas registrales en las leyes de propiedad industrial hace que, en los casos necesarios y con más frecuencia de la deseable, haya que acudir a otros cuerpos legislativos distintos de los que regulan la propiedad industrial. [...] esta situación genera una fuerte inseguridad jurídica. existe inseguridad en cuanto a la vía para dicho reflejo registral y el tipo de asiento a extender, pero también en cuanto a cuál sea su régimen jurídico, requisitos y efectos respecto de terceros. [...]”
} 
constituem a partir do ato de criação, o que não demanda qualquer expediente formal. A autoria confere o direito de exclusividade sobre a obra, o que pode ser comprovado por qualquer meio lícito.

\section{Dever de Zelo à Garantia da PI}

É amplamente difundida a ideia de que os Direitos de Propriedade Intelectual são fatores relevantes para o desenvolvimento socioeconômico das nações. Reis (2020) argumenta que:

Os Estados vêm percebendo que as diversas legislações relativas à PI, embora instituam, como regra, direitos de exclusividade que interferem nos princípios da livre iniciativa (Constituição Federal, art. $1^{\circ}$, inciso IV) e da livre concorrência (Constituição Federal, art. 170, inciso IV), possuem, quando implementadas de forma adequada, a característica de incentivar os frutos originados pela atividade intelectiva humana [...] em virtude de conferir (em regra, por determinado período de tempo) uma segurança moral e patrimonial àqueles que procedem a criações ou aperfeiçoamentos intelectuais em diversas áreas, o que impulsiona o estímulo ao desenvolvimento científico, tecnológico e cultural das nações e se reflete de maneira positiva em inúmeros setores, como o da economia. [...] $\mathrm{O}$ ordenamento jurídico nacional estabelece que a atuação da Administração Pública na promoção dos direitos de Propriedade Industrial deve ter em vista o interesse social e o desenvolvimento tecnológico e econômico do País (art. $5^{\circ}$, inciso XXIX, da Constituição Federal), além de se submeter ao comando geral da função social da propriedade (art. $5^{\circ}$, inciso XXIII, da Constituição Federal) [...].

Consta da Estratégia Nacional de Propriedade Intelectual ${ }^{11}$, elaborada pelo Grupo Interministerial de Propriedade Intelectual - GIPI (Brasil, 2020, p. 28) que:

[...] a criatividade e a inovação têm sido uma constante em nações com bom desempenho e crescimento econômico. É estratégico para o Brasil que a criatividade e a inventividade se transformem em geração de riqueza para o país, favorecendo o desenvolvimento econômico e sociocultural. Portanto, é imperativo que as potencialidades sejam conduzidas adequadamente por pequenos negócios, médias e grandes empresas, sejam negócios tradicionais ou provenientes de indústrias emergentes ou intensivas em propriedade intelectual (PI), além de instituições de ensino e pesquisa e governo, para a conversão da criatividade e da inventividade em bens e serviços inovadores e competitivos nacional e internacionalmente.

A liberdade de criar e inovar é acompanhada do compromisso em resguardar interesses econômicos relacionados, especialmente quando a atividade de P,D\&I é viabilizada a partir de recursos de fomento e envolve interesses de diversos atores e agentes econômicos. Assim, a portaria do CNPq estabelece ao bolsista, ao pesquisador e ao responsável por auxílios e bolsas outorgados, o dever de zelar pela proteção da propriedade intelectual gerada a partir de projetos financiados $\left(\text { Art. } 3^{\circ} \text {, I }\right)^{12}$.

Tal compromisso estende-se por todo o período de realização do projeto, considerando que as atividades de P,D\&I, embora assumam parâmetros e objetivos do ponto de vista de ações e metas de projeto, não raro defrontam-se com novos desafios ao longo da sua execução, cujas soluções técnicas emergentes podem ser objeto de tutela industrial. (Art. $3^{\circ}$, II) ${ }^{13}$.

Desde 2004, a Lei nº 10.973 (chamada Lei de Inovação) determinou que as Instituições Científicas, Tecnológicas e de Inovação (ICTs) públicas disponham de Núcleos de Inovação Tecnológica, próprios ou em associação com outras ICTs (Art.

\footnotetext{
${ }^{11}$ Que, sistemicamente, complementa-se com a Estratégia Nacional de Ciência, Tecnologia e Inovação, a qual "no campo específico da política pública de CT\&I, o desafio de coordenação diante de uma realidade federativa heterogênea e plural foi considerado na ENCTI 2016-2022, ao se apresentar a gama de atores que irão compor e atuar no Sistema Nacional de Ciência, Tecnologia e Inovação - SNCTI." (Muraro et. al, 2021, p. 9)

12 “Art. $3^{\circ}$ Compete ao bolsista, ao pesquisador e ao responsável por auxílios e bolsas outorgados pelo CNPq, no Brasil ou no exterior: I - zelar pela proteção da propriedade intelectual gerada a partir de projetos financiados pelo CNPq; e [...]"

13 "II - verificar, a qualquer tempo, se a execução do projeto produz ou poderá produzir resultado potencialmente objeto de Patente de Invenção, Patente de Modelo de Utilidade, Registro de Desenho Industrial, Registro de Programa de Computador, Certificado de Proteção de Cultivar ou Registro de Topografia de Circuito Integrado."
} 
16), aos quais compete, entre outras obrigações, avaliar e classificar os resultados decorrentes de atividades e projetos de pesquisa, a fim de opinar pela conveniência e promover a proteção das respectivas criações.

Muraro (2020, p. 111) esclarece que o papel dos NITs é "central na consolidação do Marco Legal da CT\&I e da Política de Inovação de ICTs". Nesse contexto, a comunicação de invento, bem como a demanda por consultas e orientações deve assumir contornos institucionais ${ }^{14}$.

Práticas e posturas acauteladoras, no sentido de reconhecer possibilidades de reivindicação de títulos de PI, embora contem com o apoio dos NITs, representam competências que devem ser incorporadas ao repertório dos pesquisadores, gestores e bolsistas envolvidos. A efetividade da comunicação de invento ${ }^{15}$, assim como o êxito da obtenção de garantias de PI dependem disto. Sobre o assunto, entre outros aspectos, a portaria CNPq determina que "o bolsista ou pesquisador, quando do preenchimento da Proposta de Auxílio a Pesquisa na Plataforma Carlos Chagas, deverá classificar sua pesquisa quanto ao potencial de gerar uma propriedade intelectual a ser protegida" (Art. 12). No ambiente acadêmico, a publicação dos resultados das pesquisas é prática corrente. Contudo, diante da necessidade de resguardar o requisito da novidade exigido para a obtenção de patentes de invenções e modelos de utilidade, bem como registros de desenhos industriais, a comunicação e articulação entre as partes envolvidas é fundamental para gerir os parâmetros e o tempo à publicação das criações.

Como já referido, o CNPq apoia majoritariamente projetos de desenvolvimento científico e tecnológico oriundos do ambiente acadêmico. Ocorre que a avaliação dos programas de pós-graduação das Universidades, realizada pela CAPES, ainda considera a publicação de artigos como critério determinante. Disso resulta a necessidade do avanço institucional em relação as atividades de fomento nas três esferas públicas, com vistas a instituição de normas, a exemplo do CNPq, voltadas a equacionar o acesso ao conhecimento e a sustentabilidade econômica nacional. Siqueira (2018, p. 19) pondera que algumas áreas de conhecimento da CAPES reconhecem as patentes como produção científica relevante, o que leva alguns programas de pósgraduação exigirem como um dos requisitos para a conclusão do curso, alternativamente, a publicação de artigo ou o depósito de pedido de patente.

A efetiva publicação de um artigo em periódico científico demanda avaliação prévia, cujos critérios procuram atestar a qualidade e confiabilidade do estudo. A rigor, o depósito de uma patente equivale a submissão de um artigo à revista. Ou seja, o monopólio industrial só se confirma após avaliação técnica dos requisitos de patenteabilidade por parte do INPI, assim como a publicação de um artigo só se efetiva após avaliação e aprovação por pares. Contudo, é importante considerar que a produção do relatório descritivo e das reivindicações que instruem o depósito de patente, quando acompanhada pelo Núcleo de Inovação Tecnológica, pressupõe qualidade e esmero técnico. De modo geral, diversos aspectos são levados em consideração pelas ICTs, antes do efetivo protocolo do pedido de patente, dentre os quais é possível citar: avaliação do estado da técnica por meio de busca de anterioridade, avaliação de potencial inovador, escritura do relatório descritivo e das reivindicações. Todas essas etapas contam, necessariamente com a efetiva atuação dos inventores, em diálogo permanente com a equipe técnica dos NITs, o que justifica sua qualificação meritória, ainda que eventualmente o privilégio industrial não seja efetivamente obtido no futuro.

A norma administrativa em comento, considera fundamental garantir a proteção, sem prejudicar a publicação pretendida, assim como a divulgação de informações relacionadas com projetos não podem prejudicar a eventual obtenção de

\footnotetext{
14 “ $§ 1^{\circ}$ Poderá ser solicitada ajuda ao Núcleo de Inovação Tecnológica (NIT) ou ao órgão/área responsável pela área de propriedade intelectual da Instituição Científica e Tecnológica (ICT) ou da empresa que sedia o projeto."

15 " $\S 2^{\circ}$ Confirmada a hipótese do inciso II do caput deste artigo, o NIT ou o órgão/área responsável pela área de propriedade intelectual da ICT ou da empresa que sedia o projeto deverá ser comunicado."
} 
proteção para a propriedade intelectual (Art. $3^{\circ}, \S 3^{\circ}, \mathrm{I} ;$ Art. $\left.4^{0}\right)^{16}$. O "período de graça"17, reconhecido especialmente no Brasil ${ }^{18}$, quando da hipótese de pedido de patente promovido pelo inventor, contribui para o equilíbrio entre a divulgação científica e o requisito da novidade. Em outras palavras, caso o conteúdo de um invento seja objeto de publicação científica, antes do depósito do pedido de patente, este poderá ser providenciado no prazo de um ano contado da data da publicação, sem prejuízo do requisito.

Porém, há que se considerar que esse benefício não integra o sistema patentário de outros países, o que torna a publicação um procedimento que inviabiliza a reivindicação do título em âmbito internacional. Nesse sentido, embora o período de graça represente uma certa vantagem no Brasil, na medida do possível, é recomendável que a publicação de trabalhos científicos relacionados à tecnologia patenteável seja feita somente após a decisão sobre eventual interesse no monopólio industrial e respectivos encaminhamentos. Cumpre observar ainda que, no âmbito da Lei de Inovação, é clara a exigência de confidencialidade em relação àqueles que tenham participado diretamente do desenvolvimento de criação ou tomado conhecimento por força de suas atividades, sem autorização expressa da respectiva ICT (Brasil, Lei. nº 10.973/04, art. 12).

\section{Propriedade Intelectual: Titularidade, Gestão e Partilha de Resultados}

A portaria em comento é taxativa no sentido de, em regra, não reconhecer ao CNPq a participação na titularidade da propriedade intelectual decorrente de projetos por ele financiados (Art. $\left.5^{\circ}\right)^{19}$, bem como não lhe cabe participação nos ganhos econômicos advindos das criações correspondentes. (Art. 10) ${ }^{20}$. Complementarmente, em instrumentos jurídicos negociais firmados pelo CNPq, nos quais constem cláusulas disciplinando Propriedade Intelectual, deverá constar a ressalva no sentido de que "as opiniões, hipóteses, conclusões ou recomendações expressas nas criações intelectuais resultantes de pesquisas apoiadas por instrumentos de fomento - auxílios e bolsas - disponibilizados pelo CNPq, são de responsabilidade do(s) autor(es)”, não refletindo necessariamente a visão do ente estatal (Art. 14).

Por sua vez, cumpre aos executores de projetos financiados e respectivos parceiros: definir as responsabilidades de gestão e assumir o custeio dos procedimentos de registro e/ou depósito (Art. $\left.9^{\circ}, \mathrm{I}\right)^{21}$, bem como definir a titularidade da PI e a eventual partilha de resultados $\left(\text { Art. } 6^{\circ}\right)^{22}$, respeitando a normativa aplicável a cada caso (Art. $9^{\circ}$, II) ${ }^{23}$. Note-se que a ausência de

16 “§ $3^{\circ} \mathrm{Na}$ hipótese do projeto produzir resultado conforme previsto no inciso II do caput deste artigo, o NIT ou o órgão responsável pela área de propriedade intelectual da ICT ou da empresa deverá ser comunicado sobre a publicação dos resultados em periódicos, anais de congressos, dissertações ou teses, ou em qualquer outra forma de divulgação, sendo que: I - nos casos pertinentes, o NIT, o órgão responsável pela área de propriedade intelectual na ICT ou na empresa devem tomar as providências para garantir a proteção, sem prejudicar a publicação pretendida.

Art. $4^{\circ} \mathrm{A}$ divulgação de informações relacionadas com o projeto não pode prejudicar a eventual obtenção de proteção para a propriedade intelectual sobre os conhecimentos gerados com o apoio do CNPq."

17 “Art. 12. Não será considerada como estado da técnica a divulgação de invenção ou modelo de utilidade, quando ocorrida durante os 12 (doze) meses que precederem a data de depósito ou a da prioridade do pedido de patente, se promovida: I - pelo inventor; II - pelo Instituto Nacional da Propriedade Industrial - INPI, através de publicação oficial do pedido de patente depositado sem o consentimento do inventor, baseado em informações deste obtidas ou em decorrência de atos por ele realizados; ou III - por terceiros, com base em informações obtidas direta ou indiretamente do inventor ou em decorrência de atos por este realizados." (Brasil, Lei. n 9.279/1996)

${ }^{18} \mathrm{Em}$ regra, para outras nações, a publicação da tecnologia por qualquer meio implica na sua inclusão no estado da técnica, mesmo que realizada pelo inventor.

19 “Art. $5^{\circ} \mathrm{O}$ CNPq não participará, em regra, da titularidade da propriedade intelectual gerada a partir dos projetos de pesquisa e bolsas financiados nos casos em que os parceiros observem as recomendações e os deveres disciplinados nesta Portaria.”

20 “Art. 10. Salvo determinações expressas na legislação, normas, convênios, acordos ou chamadas do CNPq, não lhe caberá participação nos ganhos econômicos resultantes da exploração comercial das criações protegidas decorrentes de projetos por ele financiados."

21 "Art. $9^{\circ}$ As instituições ou empresas executoras de projetos e demais parceiros deverão assumir as seguintes obrigações: I - assumir os custos do registro e/ou depósito da propriedade intelectual no Brasil e/ou exterior, bem como a gestão financeira e administrativa das ações subsequentes;"

22 "Art. $6^{\circ}$ Caberá à(s) instituição(ões) executora(as) de projetos e demais parceiros, conforme suas normativas internas e em observância da legislação federal, definir(em) a titularidade ou cotitularidade sobre criações intelectuais decorrentes de resultados de projetos de pesquisa e bolsas financiadas, integral ou parcialmente, pelo CNPq, bem como os procedimentos administrativos referentes ao registro ou depósito de pedido de proteção intelectual, no Brasil e/ou exterior e os encargos periódicos de manutenção dos mesmos."

23 “Art. $9^{\circ}$ [...] II - assegurar o compartilhamento dos ganhos econômicos advindos da exploração comercial da propriedade intelectual com os pesquisadores criadores da propriedade intelectual, de acordo com as normas das instituições ou empresas parceiras e da Lei de Propriedade 
estipulação destes aspectos pode ensejar, por parte do CNPq, a suspensão dos recursos, o que se dará mediante prévia apuração do Serviço de Suporte à Propriedade Intelectual do CNPq - SESPI (Art. $\left.7^{\circ}, 8^{\circ}\right)^{24}$.

$\mathrm{Na}$ apuração, há de se considerar critérios de conveniência adotados pelos envolvidos, bem como levar em conta o princípio da estrita legalidade, sob pena de interferência indevida nos negócios jurídicos que, mesmo com caráter publicístico, envolvem pretensões de pessoas jurídicas de direito privado.

No contexto das obrigações estabelecidas, observa-se que, se por um lado, exige-se dos executores de projetos a atenção e providência no sentido de garantir a proteção da propriedade intelectual relacionada, por outro, exige-se de igual modo que os meios de proteção não prejudiquem ou impeçam "o desenvolvimento de novas tecnologias e inovações baseadas no conhecimento compartilhado" em razão do título (Art. $9^{\circ}$, III) $)^{25}$.

Os executores e aqueles vinculados ao projeto deverão dar publicidade, via Curriculum Lattes, de pedido e concessão de depósito/registro da proteção intelectual, assim como de eventual licenciamento ou comercialização da tecnologia. (Art. $9^{\circ}$, IV e V $)^{26}$. Tal providência contribui para a articulação informacional entre as ICTs e os agentes econômicos interessados em inovação, o que pode ser considerado um desdobramento do princípio da publicidade (Art. 37 da CRFB/88).

Por certo, o cuidado em garantir a proteção de Direitos de Propriedade Intelectual visa oferecer condições juridicamente apropriadas para o ingresso de tecnologias no mercado. Dinamizar a inovação com o propósito de incrementar a economia pressupõe visão estratégica, no sentido de considerar oportunidades de licenciamento e comercialização, bem como operar transferências de tecnologias que contribuam com o desenvolvimento econômico e social. Assim, a portaria estabelece como obrigação das ICTs atuar proativamente nesse sentido, conferindo destinação econômica adequada aos bens intelectuais desenvolvidos. (Art. $9^{\circ}$, VII e VIII) ${ }^{27}$. Considerando esse contexto, pode-se afirmar que tal exigência alinha-se ao princípio da eficiência ${ }^{28}$ (Art. 37, CRFB/88), sendo o licenciamento/transferência de tecnologia um "meio" para o "fim" da função social da inovação, consoante aos objetivos socioeconômicos propostos constitucionalmente pelo Marco Legal da Ciência, Tecnologia e Inovação, pois que, para este princípio, "os meios não são fins, isto é, eles devem ser instrumentais aos fins." (Nohara, 2020).

Contudo, na hipótese dos titulares da propriedade intelectual perderem o interesse na manutenção do direito, "a instituição executora deverá, no prazo máximo de 90 (noventa) dias antes de qualquer obrigação relativa à propriedade intelectual, entrar em contato com os inventores relacionados no depósito e verificar a possibilidade de cessão de titularidade a estes." (Art. 13). Nesse mesmo sentido, a Lei de Inovação estabelece que a ICT poderá ceder seus direitos sobre a criação ao(s) respectivo(s) criador(es), a título não oneroso, mediante manifestação expressa e motivada proferida pelo órgão ou autoridade

Industrial (Lei n ${ }^{\circ}$ 9.279, de 14 de maio de 1996), do Marco Legal de Ciência, Tecnologia e Inovação (EC ${ }^{\circ} 85$, de 26 de fevereiro de 2015; Leis $n^{\circ} 10.973$, de 2 de dezembro de 2004 e $n^{\circ} 13.243$, de 11 de janeiro de 2016; e Decreto $n^{\circ} 9.283$, de 7 de fevereiro de 2018) e do Decreto $n^{\circ} 2.553$, de 16 de abril de 1998, quando aplicável;"

24 “Art. $7^{\circ}$ Compete ao Serviço de Suporte à Propriedade Intelectual do CNPq (SESPI) identificar ou receber eventuais comunicações relacionadas ao não cumprimento desses compromissos e opinar de forma motivada e conclusiva sobre o caso.

$\S 1^{\circ}$ Havendo necessidade de diligências, o SESPI poderá solicitar aos setores técnicos do CNPq parecer motivado e conclusivo sobre a matéria.

$\S 2^{\circ} \mathrm{O}$ parecer do SESPI será encaminhado ao Diretor da área que, concordando, enviará para a Diretoria Executiva do CNPq (DEx) determinar as medidas cabíveis.

Art. $8^{\circ} \mathrm{O} \mathrm{CNPq}$, com base no parecer do SESPI, poderá suspender a liberação de recursos de projetos apoiados pelo Conselho, caso os compromissos estabelecidos nesta Portaria não sejam cumpridos pelos bolsistas, pesquisadores, instituição(ões) executora(s) e parceira(s)".

25 "III - evitar o estabelecimento de qualquer forma de proteção intelectual cujas reivindicações venham a provocar uma restrição que prejudique ou impeça o desenvolvimento de novas tecnologias e inovações baseadas no conhecimento compartilhado pelo depósito de pedido de patentes, registro e/ou certificado;”

26 "IV - tornar público, por meio de informação inserida na Plataforma Lattes, quando da realização do pedido de depósito ou de registro da proteção intelectual, bem como de sua eventual concessão ou não; V - tornar público, por meio de informação inserida na Plataforma Lattes, quando do licenciamento ou comercialização da proteção intelectual, respeitadas as eventuais cláusulas contratuais que restrinjam a divulgação pública;"

${ }^{27}$ VII - no caso do titular ser uma ICT, buscar oportunidades de licenciamento e comercialização para a referida propriedade intelectual; e VIII - buscar opções de utilização e transferência de tecnologia que venham a contribuir para o desenvolvimento econômico e social do País."

${ }^{28}$ A observação de Nohara (2020) quanto à eficiência em principiologia publicística administrativista e a dinamização mercadológica é bastante pertinente: "Ocorre que a eficiência presente na administração privada não pode ser transplantada simplesmente para a administração pública, pois enquanto aquela objetiva lucro e, para tanto, as empresas devem se esmerar na permanente tarefa de adequação às exigências cambiantes do mercado, esta se preocupa, no mais das vezes, com a consecução dos interesses públicos e também com a permanente prestação de serviços públicos.” 
máxima da instituição, ouvido o Núcleo de Inovação Tecnológica. Já no caso de cessão a terceiro, tal expediente poderá também ocorrer, contudo, mediante remuneração (Brasil, Lei nº 10.973/04, art. 11 e parágrafo único).

\section{Acesso às Informações}

O caráter estatal do CNPq reveste seus atos de necessária publicidade (Art. 11)29. Para Salgado (2020), "o direito de acesso à informação é constitutivo de uma República Democrática, pois é indispensável para o exercício pleno dos direitos fundamentais." Contudo, Reis (2020) observa que:

A despeito de se considerar inquestionável a publicidade dos atos praticados pelos órgãos e entidades da Administração Pública, o desenvolvimento de tecnologias requer, a priori, um ambiente em que é imprescindível o sigilo das informações, principalmente quando presentes as tecnologias patenteáveis a serem desenvolvidas em parceria com empresas privadas, as quais poderão exigir cláusulas de exclusividade para firmar a referida parceria.

No contexto da Lei de Acesso à Informação, o sigilo de informações relacionadas a projetos de pesquisa e desenvolvimento científicos ou tecnológicos é admitido, na hipótese de garantir a segurança da sociedade e do Estado, o que se reconhece, entre outras situações, quando houver prejuízo ou risco para projetos de P\&D (BRASIL, Lei nº 12.527/11, art. 22, § $1^{\circ}$ e art. $\left.23, \mathrm{VI}\right)$.

O teor dos projetos e relatórios técnicos submetidos à editais de fomento podem conter informações que digam respeito aos bens intelectuais correspondentes. Assim, para não comprometer a proteção da propriedade intelectual envolvida, a portaria estabelece acesso restrito aos projetos e relatórios, até aprovação final do CNPq (Art. 11, I) ${ }^{30}$. Tal condição não impedirá a publicação de dados primários como "título, resumo, objeto, proponente(s), instituição(ões) executora(s) e recursos aplicados" (Art. 11, III) $)^{31}$.

De todo modo, eventual interesse na restrição de acesso público do projeto, a fim de garantir direitos de PI, deve ser manifestado junto a sua submissão (Art. 11, II) $)^{32}$, o que será respeitado pelo CNPq pelo prazo de 5 anos (Art. 11, $\left.\S 1^{\circ}\right)^{33}$. Tal compromisso implica em evidente reciprocidade, de modo que os responsáveis pelo projeto deverão assegurar que todos os envolvidos se obriguem de igual modo (Art. 11, IV) ${ }^{34}$.

Ainda é importante considerar que, embora o sigilo seja um aspecto importante no desenvolvimento de projetos de P,D\&I, em especial para a preservação de requisitos exigidos para obtenção de títulos de Propriedade Intelectual, providências nesse sentido devem ser compatibilizadas com o necessário compartilhamento de informações entre pesquisadores e instituições de pesquisa para fins acadêmicos (Art. 11, § $\left.2^{\circ}\right)^{35}$.

\footnotetext{
29 “Art. 11. As informações geradas com a implementação das propostas selecionadas e disponibilizadas na base de dados do CNPq serão consideradas de acesso público, observadas as disposições abaixo: [...]"

30 “Art. 11 [...] I - as informações constantes nos projetos e nos relatórios técnicos apresentados pelos pesquisadores e/ou bolsistas para o CNPq, enquanto estes estiverem em desenvolvimento, terão acesso restrito até o ato decisório referente à aprovação final pelo CNPq;"

31 “Art. 11 [...] III - o CNPq disponibilizará, a seu critério, as informações primárias de todos os projetos, tais como: título, resumo, objeto, proponente(s), instituição(ões) executora(s) e recursos aplicados pelo órgão;”

32 “Art. 11 [...] II - os pesquisadores cujos projetos submetidos ao CNPq, aprovados ou não, e/ou seus relatórios técnicos apresentados que possam gerar, no todo ou em parte, resultado potencialmente objeto de Patente de Invenção, Modelo de Utilidade, Desenho Industrial, Programa de Computador ou qualquer forma de proteção pelos direitos de Propriedade Industrial, deverão manifestar explicitamente o interesse na restrição de acesso na ocasião da submissão do projeto e/ou do envio do relatório técnico;"”

33 “Art. $11[\ldots] \S 1^{\circ}$ As obrigações de sigilo e restrição de acesso público previstas no Inciso II do caput deste artigo subsistirão pelo prazo de 5 (cinco) anos a partir da solicitação da restrição."

34 “Art. 11 [...] IV - as partes deverão assegurar que cada um de seus empregados, funcionários, agentes públicos e subcontratadas, que tenham acesso às informações de acesso restrito, tenham concordado em cumprir as obrigações de restrição de acesso à informação."

35 “Art. $11[\ldots] \S 2^{\circ}$ Em que pese a possibilidade de restrição de acesso público previstas no Inciso II do caput deste artigo, esta não reduz, contudo, a responsabilidade que os pesquisadores, suas equipes e instituições têm, como membros da comunidade de pesquisa, de manter, sempre que possível, os resultados da pesquisa, dados e coleções à disposição de outros pesquisadores para fins acadêmicos."
} 


\section{Solução Adequada de Conflitos}

A norma estipula uma previsão conciliatória e arbitral para dirimir conflitos atinentes a ela (Art. 17) ${ }^{36}$. Acerca da solução adequada de conflitos que podem envolver a Administração Pública:

Hoje em dia há um sistema multiportas, isto é, há mais de uma modalidade para a solução do conflito envolvendo a Administração. Isso porque o ordenamento jurídico coloca à disposição da Administração várias formas de solução de suas controvérsias, muitas vezes, de forma sucessiva. A escolha da "porta" ou "portas" para resolver a controvérsia deve ser aquela que se mostre mais adequada ao caso concreto. De tal modo, a arbitragem é uma das formas pelas quais a Administração pode resolver os seus conflitos. Vale dizer, a escolha pela via arbitral é uma opção feita pelo administrador no uso de sua competência discricionária. [...] Quanto à escolha da câmara, é conveniente que a Administração adote procedimento preliminar que assegurem a economicidade das prestações, a adequação e qualificação dos serviços e dos regulamentos etc. Assim, previamente à celebração do contrato administrativo com o particular, a Administração deve realizar um procedimento administrativo, visando selecionar, cadastrar ou credenciar instituições arbitrais. (Oliveira, Estefam, 2020)

Por mais que a discussão sobre questões relativas à validade/patenteabilidade de uma invenção não possam se dar diretamente pela via arbitral no Brasil ${ }^{37}$, as questões pertinentes às atribuições do CNPq e sua "divisão de propriedade intelectual" (SESPI) com as obrigações atribuídas por estes aos executores de projetos são passíveis de discussão.

\section{Considerações Finais}

O CNPq contribui para que pesquisadores e ICTs proponham e desenvolvam projetos potencialmente transformadores da realidade social e econômica do país.

A aplicação industrial e mercantil dos resultados ${ }^{38}$ de pesquisas científicas e tecnológicas é cada vez mais levada em consideração no ambiente acadêmico. Nesse sentido, as ICTs (sobretudo, as Universidades) têm o compromisso de disseminar o conhecimento para a sociedade, integrando a função social e a função econômica das pesquisas, inovações e invenções. Ao abordar o contexto patentário para as Universidades Públicas, Campillo (2016) assevera que:

Las universidades son instituciones esenciales en el sistema de investigación, por cuanto llevan a cabo una significativa tarea de investigación científica y desarrollo tecnológico, que en muchos casos se traduce en la generación de invenciones protegibles mediante alguna de las figuras reguladas por el Derecho de Propiedad Industrial. [...] Atendiendo a la importancia de su papel en la generación de conocimiento, las universidades han de considerarse actores esenciales del proceso de desarrollo económico y social.

O conhecimento, quando disponível apenas por meio de publicações científicas comerciais ${ }^{39}$, permanece limitado a uma espécie de bolha acadêmica de alcance restrito. Por outro lado, dezoito meses após o seu protocolo, todo conteúdo técnico de um pedido de patente torna-se público ${ }^{40}$. Soma-se a esse aspecto o fato de que as "patentes contém informações tecnológicas que geralmente não estão disponíveis em outros documentos” (Barroso et. al, 2009, p. 207). Significa dizer que, em sentido amplo,

\footnotetext{
36 “Art. 17. Para dirimir eventuais dúvidas e questionamentos decorrentes da política apresentada nesta Portaria, que não possam ser solucionadas por entendimento administrativo direto entre as Partes, fica eleita a Câmara de Conciliação e Arbitragem da Administração Federal (CAAF), e, para as hipóteses em que não for possível a solução amigável de eventual controvérsia, o Foro da Justiça Federal, Seção Judiciária do Distrito Federal, com exclusão de qualquer outro, mesmo privilegiado."

${ }^{37}$ Para uma literatura específica e aprofundada sobre Arbitragem e Propriedade Intelectual, vide, dente outros, Brauer (2018).

38 "La invención es una de las posibles manifestaciones de la investigación universitaria cuando esta última alcanza la dimensión de resultado." (García, 2017)

${ }^{39}$ No que diz respeito às Instituições de Ensino Superior, recomenda-se o documentário Paywall: The Business of Scholarship (2018), o qual estabelece uma crítica relevante acerca da distribuição de artigos científicos em grandes bases bastante onerosas à instituições de ensino superior, e a relação entre a falta de acesso justo e razoável com a emergente 'pirataria' desta modalidade de conteúdo.

40 “Art. 30. O pedido de patente será mantido em sigilo durante 18 (dezoito) meses contados da data de depósito ou da prioridade mais antiga, quando houver, após o que será publicado [...] $§ 2^{\circ} \mathrm{Da}$ publicação deverão constar dados identificadores do pedido de patente, ficando cópia do relatório descritivo, das reivindicações, do resumo e dos desenhos à disposição do público no INPI” (BRASIL, Lei 9.279/96).
} 
a reivindicação de títulos de propriedade intelectual assume o papel de mecanismo de garantia de direitos de exclusiva, e de indutor de inovações públicas a partir da divulgação do conhecimento científico e tecnológico relacionado.

De modo geral, a humanidade está "constantemente em busca da resolução dos seus problemas, sejam simples ou complexos, levando-o a manipular o ambiente material e imaterial que o rodeia em busca de possíveis soluções” (Reis, 2020). O conhecimento é para todos, pois que "nas atividades de pesquisa científica a liberdade prepondera e só encontra limites quando a Lei e as normas éticas impõem determinadas condutas e com claras notas de utilidade pública" (Vale, 2018, p. 274).

A norma do CNPq traz o aprimoramento da publicação da pesquisa e, ao mesmo tempo, procura garantir o retorno dos investimentos públicos. Nessa perspectiva, cumpre a CAPES aperfeiçoar o modelo avaliativo dos programas nacionais de pósgraduação, bem como cabe as Fundações Estaduais de Amparo à Pesquisa (FAPs) e demais instituições públicas em âmbito municipal, estabelecerem critérios de disponibilidade à recursos públicos que possibilitem acesso ao conhecimento produzido com pesquisas e fortaleçam a geração de ativos intangíveis.

Considerando esses fatores, a atuação dos Núcleos de Inovação Tecnológica torna-se ainda mais estratégica no sentido de orientar as atividades de pesquisa e contribuir para o desenvolvimento de competências relacionadas a reivindicação de títulos consistentes de propriedade intelectual. Sugere-se estudos futuros que possam contribuir com o aprimoramento do zelo à garantia da PI nas ICTs, assim como voltados a propor metodologias diagnósticas relacionadas.

\section{Agradecimentos}

Os autores agradecem a Fundação Universidade Regional de Blumenau (Proj. SIPEX 772/2019), Fundação de Amparo à Pesquisa e Inovação do Estado de Santa Catarina - FAPESC (2019TR1181), e ao Conselho Nacional de Desenvolvimento Científico e Tecnológico - CNPq (304560/2020-0).

\section{Referências}

Ávila, H. B. (2019). Teoria da segurança jurídica. Juspodivm, Malheiros.

Barbosa, D. B. (2014). Tratado da propriedade intelectual. Lumen Juris. [Tomo III]

Bardin, L. (2016). Análise de conteúdo. Edições 70.

Barroso, W., Quoniam, L., \& Pacheco, E. (2009). Patents as technological information in Latin America. World Patent Information, 31 (31). 207-215. https://doi.org/10.1016/j.wpi.2008.11.006

Brasil. CNPq. (2014). Resolução Normativa 034/2014. http://memoria2.cnpq.br/web/guest/view/-/journal_content/56_INSTANCE_0oED/10157/2118692

Brasil. CNPq. (2008). Resolução Normativa no 013/2008. http://memoria2.cnpq.br/web/guest/view/-/journal_content/56_INSTANCE_0oED/10157/24829

Brasil. CNPq. (1998). Resolução Normativa no 014/1998. http://memoria2.cnpq.br/web/guest/view/-/journal_content/56_INSTANCE_0oED/10157/28764

Brasil. CNPq. (1981). Resolução 114, de 1981.

Brasil. CNPq. (1981). Resolução 115, de 1981.

Brasil. (1988) Constituição da República Federativa do Brasil. http://www.planalto.gov.br/ccivil_03/Constituicao/ConstituicaoCompilado.htm

Brasil. (2018). Decreto $n^{\circ}$ 9.283, de 7 de fevereiro de 2018. Regulamenta a Lei $\mathrm{n}^{\mathrm{o}} 10.973$, de 2 de dezembro de 2004 , a Lei $\mathrm{n}^{\mathrm{o}} 13.243$, de 11 de janeiro de 2016 , o art. $24, \S 3^{\circ}$, e o art. $32, \S 7^{\circ}$, da Lei $n^{\circ} 8.666$, de 21 de junho de 1993 , o art. $1^{\circ}$ da Lei $n^{\circ} 8.010$, de 29 de março de 1990 , e o art. $2^{\circ}$, caput, inciso I, alínea "g", da Lei $\mathrm{n}^{\circ} 8.032$, de 12 de abril de 1990 , e altera o Decreto ${ }^{\circ} 6.759$, de 5 de fevereiro de 2009 , para estabelecer medidas de incentivo à inovação e à pesquisa científica e tecnológica no ambiente produtivo, com vistas à capacitação tecnológica, ao alcance da autonomia tecnológica e ao desenvolvimento do sistema produtivo nacional e regional. http://www.planalto.gov.br/ccivil_03/_Ato2015-2018/2018/Decreto/D9283.htm

Brasil. (2019). Decreto $n^{o} 10.139$, de 28 de novembro de 2019. Dispõe sobre a revisão e a consolidação dos atos normativos inferiores a decreto. http://www.planalto.gov.br/ccivil_03/_Ato2019-2022/2019/Decreto/D10139.htm

Brasil. (2004). Lei $n^{\circ} 10.973$, de 2 de dezembro de 2004. Dispõe sobre incentivos à inovação e à pesquisa científica e tecnológica no ambiente produtivo e dá outras providências. http://www.planalto.gov.br/ccivil_03/_ato2004-2006/2004/lei/L10.973compilado.htm 
Brasil. (2007). Lei $n^{o} 11.484$, de 31 de maio de 2007. Dispõe sobre os incentivos às indústrias de equipamentos para TV Digital e de componentes eletrônicos semicondutores e sobre a proteção à propriedade intelectual das topografias de circuitos integrados [...]. http://www.planalto.gov.br/ccivil_03/_ato20072010/2007/lei/L11484compilado.htm

Brasil. (2011). Lei $n^{\circ} 12.527$, de 18 de novembro de 2011. Regula o acesso a informações previsto no inciso XXXIII do art. 5 , no inciso II do $§ 3^{\circ}$ do art. 37 e no $\S 2^{\circ}$ do art. 216 da Constituição Federal, altera a Lei $\mathrm{n}^{\circ} 8.112$, de 11 de dezembro de 1990 , revoga a Lei $\mathrm{n}^{\circ} 11.111$, de 5 de maio de 2005 , e dispositivos da Lei $\mathrm{n}^{\circ}$ 8.159, de 8 de janeiro de 1991, e dá outras providências. http://www.planalto.gov.br/ccivil_03/_ato2011-2014/2011/lei/112527.htm

Brasil. (2018). Lei $n^{\circ}$ 13.655, de 25 de abril de 2018. Inclui no Decreto-Lei $n^{\circ} 4.657$, de 4 de setembro de 1942 (Lei de Introdução às Normas do Direito Brasileiro), disposições sobre segurança jurídica e eficiência na criação e na aplicação do direito público. http://www.planalto.gov.br/ccivil_03/_ato20152018/2018/lei/L13655.htm

Brasil. (1996) Lei $n^{o}$ 9.279, de 14 de maio de 1996. Regula direitos e obrigações relativos à propriedade industrial. http://www.planalto.gov.br/ ccivil_03/Leis/L9279.htm

Brasil. (1997). Lei $n^{o}$ 9.456, de 25 de abril de 1997. Institui a Lei de Proteção de Cultivares e dá outras providências. http://www.planalto.gov.br/ ccivil_03/leis/19456.htm

Brasil. Ministério da Economia. Grupo Interministerial de Propriedade Intelectual (2020). Estratégia Nacional de Propriedade Intelectual. Brasília: Secretaria Executiva do GIPI. https://www.gov.br/inpi/pt-br/central-de-conteudo/noticias/cerimonia-marca-50-anos-do-inpi-e-lancamento-da-estrategia-nacional-depropriedade-intelectual/EstratgiaNacionaldePropriedadeIntelectual.pdf

Brauer, B. G. (2018) Arbitragem - Questões Controvertidas na Propriedade Intelectual. Lumen Juris.

Campillo, J. A. C. (2016). La Normativa de las Universidades Públicas Españolas en Materia de Propiedad Industrial: la Patente en la Universidad Pública. Thomson Reuters Aranzadi.

Giglio, D. (2019). Estrutura jurídica dos ecossistemas de inovação: parques tecnológicos. Lumen Juris.

García, L. S. (2017). Configuración jurídica de las invenciones universitarias: análisis a la luz de la Ley 24/2015, de 24 de junio, de patentes. Thomson Reuters Civitas,

González, S. N. (2016). Aspectos registrales de la propiedad industrial. Marcial Pons.

Grau, E. R. (2021). Por que tenho medo dos juízes: a interpretação/aplicação do direito e os princípios. Juspodivm, Malheiros.

Lima, M. I. (2020). Liberdade de pesquisa científica e inovação na sociedade do conhecimento: um estudo da possível aplicação da teoria do academic capitalism no Brasil. Juspodivm.

Marques Neto, F. de A. (2019). Parte III - Fomento. In: Di Pietro, M. S. Z. (Org.). Tratado de Direito Administrativo - Funções Administrativas do Estado. Thomson Reuters Revista dos Tribunais.

Minayo, M. C. de S. (2002). Ciência, técnica e arte: o desafio da pesquisa social. In: Ferreira, Minayo, M. C. de S. et al. Pesquisa social: teoria, método e criatividade. 21. ed. Editora Vozes.

Motta, F., \& Nohara, I. P. D. (2020). Coleção soluções de direito administrativo - LINDB no direito público. Thomson Reuters Revista dos Tribunais.

Muraro, L. G. \& Castro-Lucas, C. (2021). Os Desafios da Estratégia Nacional de Ciência, Tecnologia e Inovação - ENCTI 2016/2022. Revista de Empreendedorismo, Negócios e Inovação. 6 (1), p. 4-30. https://doi.org/10.36942/reni.v6i1.432

Nohara, I. P. D. (2020). Coleção soluções de direito administrativo - Administração Pública/Capítulo VII da Constituição Federal de 1988. Thomson Reuters Revista dos Tribunais.

Oliveira, G. J. de, \& Estefam, F. F. (2020). Curso prático de arbitragem e administração pública. Thomson Reuters Revista dos Tribunais.

Othon Sidou, J. M. (2016). Dicionário Jurídico: Academia Brasileira de Letras Jurídicas. Forense.

Paywall: The Business of Scholarship. (2018). https://paywallthemovie.com/

Portela, B. M., Melo Barbosa, C. M., Muraro, L. G., \& Dubeux, R. (2020). Marco legal de ciência, tecnologia e inovação no Brasil. Juspodivm.

Prolo, I., Lima, M. C., \& Silva, L. F. da. (2018). Os desafios na adoção da tradição interpretativista nas ciências sociais. Diálogo, 39, 25-37, doi: 10.18316/dialogo.v0i39.4110

Reis, R. O. (2020). Propriedade intelectual na administração pública e controle externo. Lumen Juris.

Salgado, E. D. (2020). Coleção soluções de direito administrativo - Lei de Acesso à Informação. Thomson Reuters Revista dos Tribunais.

Siqueira, C. P. de C. (2018) Por que patentear? Reflexões sobre as narrativas de pesquisadores da Universidade Federal Flumeninse. Dissertação de mestrado, Universidade Federal Fluminense, Rio de Janeiro, Brasil.

Suzigan, W., Albuquerque, E., \& Cario, S. A. F. (2011). Em busca da inovação: interação universidade-empresa no Brasil. Autêntica.

Travincas, A. C. T. (2018). A tutela jurídica da liberdade acadêmica no Brasil: a liberdade de ensinar e seus limites. Livraria do Advogado.

Vale, H. (2018). Princípios jurídicos da inovação tecnológica: aspectos constitucionais, administrativos, tributários e processuais. Lumen Juris.

Wald, A. (2010). Novas perspectivas da empresa - (Vistas por um advogado). In: Doutrinas essenciais de direito empresarial - Volume I. Thomson Reuters Revista dos Tribunais. 